\title{
An empirical study on empowering private bank workers using EFQM
}

\author{
Jafar Beikzad, Yousef Majnooni Totakhaneh and Saeid Ghorbannejad Maleki*
}

Department of Public Management, Islamic Azad University, Bonab branch, Bonab, Iran

\begin{tabular}{|c|c|}
\hline ARTICLEINFO & A B S T RACT \\
\hline $\begin{array}{l}\text { Article history: } \\
\text { Received June } 15,2011 \\
\text { Received in Revised form } \\
\text { August, } 10,2011 \\
\text { Accepted } 12 \text { August } 2011 \\
\text { Available online } \\
16 \text { August } 2011 \\
\text { Keywords: } \\
\text { EFQM } \\
\text { Enabling employee } \\
\text { Efficiency } \\
\text { Competition } \\
\text { Organizational excellence }\end{array}$ & $\begin{array}{l}\text { Empowering workers play an essential role on increasing productivity in any organization. The } \\
\text { service industries such as insurance companies or banks mostly rely on their own people to } \\
\text { retain their customers and incomes. The recent increasing trend on the number of private banks } \\
\text { in Iran has increased competition among existing banks. The banking industry strives to } \\
\text { empower its employees as much as possible in an attempt to maintain market share by not } \\
\text { losing its customers. In this paper, we present an empirical study to detect the most important } \\
\text { factors empowering bank employees. The study is implemented for a recently established } \\
\text { private bank with } 228 \text { people with } 32 \text { questions where } 15 \text { questions are focused on empowering } \\
\text { employees. The results are analyzed using statistical tests and descriptive methods. The results } \\
\text { indicate that leadership, academic qualification, appropriate policy and strategy, cooperation } \\
\text { and processes play important role on empowering and enabling bank's employee. }\end{array}$ \\
\hline
\end{tabular}

\section{Introduction}

During the past few decades, there have been tremendous efforts on developing various quality based techniques on increasing productivity of organizations such as the Deming prize in Japan, the Malcolm Baldrige national quality award model in the USA, and the European quality award or EFQM excellence model in Europe (2003). One of the primary concerns on implementing such models is to learn the effects of implementing these methods on firms' characteristics (Westlund, 2001; Inman, 2011). Kull and Wacker (2010) studied the impact of culture on implementation of total quality management (TQM) in Asian countries. They found differences of quality management among the East Asian cultures of China, South Korea, and Taiwan and found that specific cultural dimensions were statistically associated with quality management effectiveness. TQM is one of general terms used to improve the performance of organizations and it has different meanings (Prajogo \& Sohal, 2004; Rahman, 2004).

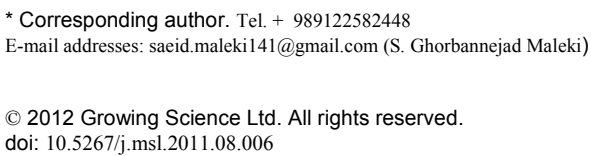


Generally speaking, TQM can be categorized as soft and hard, where the soft one is associated with human resource management and emphasize leadership, teamwork, training, and employee involvement (Rahman \& Bullock, 2005; Yong \& Wilkinson, 2001; Yusof \& Aspinwall, 2000; ). The hard issues are concerned with improving production techniques and operations and look for establishing a working method through the establishment of well-defined processes and procedures to make possible the continuous improvement of services to customers. Zhang (2000) developed a model of quality management methods and evaluating their effects on business performance for a real-world case study. He concluded that the optimal management of TQM core concepts will lead to better organizational performance. According to Sun (1999) the soft and hard components of TQM implementation must accompany each other to yield good results. TQM provides better value to the customer by determining customers' expressed and latent needs, responsiveness to changing markets, as well as through improving the efficiency of the processes, which produce the product or service (Reed et al., 1996).

Human workforce is the most important parts of any organization. Basic factor for its existence is the abilities and quality of human workforce and empowering human resource makes organization more powerful. Empowering employee is one of the effective techniques for employee productivity promotion and optimum use of their capacities and abilities reaching organizational goals. The primary objective of this paper is to study the most important factors influencing bank's efficiency such as leadership, academic qualification, appropriate policy and strategy, etc.

The organization of this paper first presents the problem statement in section 2 and details of the results of our implementation of the proposed study of this paper are given in section 3. Finally, concluding remarks are given in section 4 to summarize the contribution of the paper.

\section{Problem interpretation}

Today, organizations must be managed at completely competitive environment involved with significant changes and managers do not have much control on their authorized people. They need to spend their time for internal and external environment detection and transfer routine tasks on employees. Employees also need to have necessary skills, wisdoms and capabilities and realize organizations' goals well.

Enabling is new method for pioneer organizations existence in competitive environment. In fact, it is one of the most important concepts applied by organizations through using new procedure of organizations excellence management. This fact is important because the main advantage of resources is employee's innovations, creativities, onus and invitation of their supporting and cooperation based on enabling not new technologies. The proposed study of this paper is implemented for a private bank called Mehr bank located in east province of Azarbaijan, Iran. Mehr Bank must enable its employees to get its mission, goals and perspectives within stakeholders and customers response because employees are the fundamental wealth of every organization. This paper tries to answer this question by detecting the effective factors for empowering and enabling the bank. For this reason, the factors have been defined in 5 groups based on enabling criteria of organizational excellence model which are:

1- Leadership;

2- Policy and strategy;

3- Qualified staff and colleagues;

4- Personal results acceptance (feeling of being effective force);

5- Processes and employee enabling based on Wetten and Cameron's theory at 5 dimensions:

1- Self effectiveness (personal qualification feeling);

2- Self organizing or self authorizing (personal selecting feeling); 
3- Results personal acceptability (feeling of being effective force);

4- Being meaningful (having valuable job);

5- Trust (safety and assurance feeling) because of the assessment of effective factor on employees enabling based on criterions of organizational excellence model.

In this paper, as surveying mentioned effective factors, Whetten \& Cameron's theory based on EFQM organizational excellence model for employees enabling effective factors are held as theoretical framework (Whetten \& Cameron, 1994) with the following five dimensions,

1- Self-effectiveness,

2- Self-authority,

3- Accepting results personally,

4- Meaningfully,

5- Trust,

Table 1 shows the definition of each dimension.

\section{Table 1}

Employees enabling dimensions

\begin{tabular}{ll}
\hline Dimension & Definition \\
\hline Self-effectiveness & Personal feeling of being eligible \\
Self-authority & Personal feeling of being able to select \\
Accepting results personally & Personal feeling of being effective \\
Meaningfully & Personal feeling of having valuable jobs \\
Trust & Personal feeling of safety and confidence \\
\hline
\end{tabular}

There are five criteria of leadership, employee, policy and strategy, cooperation and resources and processes associated with the proposed study of this paper.

\subsection{Research hypothesis}

1- Leadership enabler criterion of EFQM organizational excellence model is effective on east Azarbaijan Mehr Bank employee enabling.

2- Employee enabler criterion of EFQM organizational excellence model is effective on east Azarbaijan Mehr Bank employee enabling.

3- Policy and Strategy enabler criterion of EFQM organizational excellence model is effective on east Azarbaijan Mehr Bank employee enabling.

4- Cooperation's and Resources enabler criterion of EFQM organizational excellence model is effective on east Azarbaijan Mehr Bank employee enabling.

5- Processes enabler criterion of EFQM organizational excellence model is effective on east Azarbaijan Mehr Bank employee enabling.

\section{Research methodology}

Present research has survey methodology and practical purpose. Statistical society is East Azarbaijan Mehr Bank employees consist of 228 people. The sample size, $n$, is determined as follows,

$n=\frac{\frac{t^{2} \times p \times q}{d^{2}}}{1+\frac{1}{N}\left(\frac{t^{2} \times p \times q}{d^{2}}-1\right)}$, 
where $p, q$ are the probability of acceptance and rejection, which are normally chosen as $p=q=0.5$. The other parameters $t, d$ and $N$ represent t-student, error term and population size, respectively. Applying Eq. (1) for our survey with 95\% confidence interval, i.e. $\mathrm{t}=1.95$, and 5\% error, i.e. $d=0.05$ yields $n=143$. For selecting statistical sample from statistical society, categorized random sampling has been used. Therefore, statistical society has been divided into 38 categories and they have been estimated as simple random sampling in every category after determining value of every category. Table 2 summarizes the results of the information for all 38 branches.

Table 1

Statistical sample and society with Branch separation of east Azarbaijan Mehr Bank

\begin{tabular}{|c|c|c|c|c|c|c|c|c|c|c|c|}
\hline Rank & Branch & Employee & $\begin{array}{l}\text { Share in } \\
\text { statistical } \\
\text { sample }\end{array}$ & Rank & Branch & Employee & $\begin{array}{l}\text { Share in } \\
\text { statistical } \\
\text { sample }\end{array}$ & Rank & Branch & Employee & $\begin{array}{l}\text { Share in } \\
\text { statistical } \\
\text { sample }\end{array}$ \\
\hline 1 & H.Q & 28 & 18 & 14 & Beheshti & 5 & 3 & 27 & Yaghchian & 5 & 3 \\
\hline 2 & Golgasht & 4 & 3 & 15 & Tajalayi & 5 & 3 & 28 & Mosala & 5 & 3 \\
\hline 3 & Aboreihan & 5 & 3 & 16 & KHosro.S & 5 & 3 & 29 & Mehrban & 3 & 2 \\
\hline 4 & Nour & 4 & 3 & 17 & Pashayi & 5 & 3 & 30 & Maragheh & 7 & 4 \\
\hline 5 & Azadi & 7 & 4 & 18 & Valiasr & 5 & 3 & 31 & Ajabshir & 6 & 4 \\
\hline 6 & Tractor.S & 4 & 3 & 19 & Sattar.Kh & 5 & 3 & 32 & Bostan.A & 5 & 3 \\
\hline 7 & Fahmideh & 4 & 3 & 20 & Madani & 6 & 4 & 33 & Malekan & 6 & 4 \\
\hline 8 & Shafizade & 6 & 4 & 21 & Markazi & 7 & 4 & 34 & Marand & 7 & 4 \\
\hline 9 & Bakeri & 6 & 4 & 22 & Hashtrod & 5 & 3 & 35 & SHabestar & 5 & 3 \\
\hline 10 & Mianeh & 9 & 6 & 23 & Sarab & 5 & 3 & 36 & Kaleibar & 4 & 3 \\
\hline 11 & Heris & 6 & 4 & 24 & Hadishahr & 6 & 4 & 37 & Azarshahr & 5 & 3 \\
\hline 12 & Oskou & 5 & 3 & 25 & Ahar & 5 & 3 & 38 & Tork.M.Ch & 3 & 2 \\
\hline 13 & Fajr & 8 & 5 & 26 & Bonab & 7 & 4 & Sum & & 228 & 143 \\
\hline
\end{tabular}

Data gathering tools are two questionnaires including enabler criteria of organizational excellence with 32 questions and enabling questionnaire based on Wetten and Cameron's theory with 15 questions summarized in Table 3. Note that we have used Likert (Likert, 1932) scale for all questions.

Table 3

Questionnaire questions division

\begin{tabular}{llll}
\hline Variables & dimensions & Question Rank & Question No. \\
\hline \multirow{2}{*}{$\begin{array}{l}\text { Criterions of } \\
\text { organizational }\end{array}$} & Leadership & $1-8$ & 8 \\
excellence & Academic qualification & $9-18$ & 10 \\
model & Policy and Strategy & $19-23$ & 5 \\
& Cooperation's and Resources & $24-27$ & 4 \\
\hline Enabling & Processes & $28-32$ & 5 \\
\hline
\end{tabular}

The Chronbach's Alpha (Cronbach, 1952) for the organizational excellence model and enabling parts of the questionnaire have been calculated as 0.967 and 0.903 , respectively, which means the questionnaire is valid. Table 4 summarizes some of the descriptive results for the proposed study of this research.

Table 4

Descriptive information of the proposed study

\begin{tabular}{llllllll}
\hline & Leadership & Employees & $\begin{array}{l}\text { Policy } \\
\text { Strategy }\end{array}$ & $\begin{array}{l}\text { \& } \\
\text { Resources }\end{array}$ & Processes & Enabling \\
\hline Number & 143 & 143 & 143 & 143 & 0 & 143 & 143 \\
No Answer & 0 & 0 & 0 & 11.78 & 0 & 0 \\
Average & 23.43 & 30.45 & 15.45 & 3.138 & 14.13 & 60.77 \\
S. & 6.667 & 7.223 & 3.819 & & 4.108 & 8.688 \\
Deviation & & & & & & & 75.475 \\
Variant & 28 & 31 & 16 & 13 & 5 & 45 \\
Rank & 8 & 14 & 7 & 5 & 23 & 30 \\
Min & 36 & 45 & 23 & 18 & 5 & 75 \\
Max & & & & & & \\
\hline
\end{tabular}


In order to study the relationship among the components of the proposed study of this paper we have calculated Pearson correlation for all hypotheses and Table 5 summarizes the results.

\section{Table 5}

The summary of Pearson test results

\begin{tabular}{cllll}
\hline$\propto=0.05$ & Enabling & Pearson's correlation & Sig. (1-tailed) & N \\
\hline Hypothesis 1 & Leadership & 0.298 & 0.000 & 143 \\
Hypothesis 2 & Academic qualification & 0.353 & 0.000 & 143 \\
Hypothesis 3 & Policy \& Strategy & 0.296 & 0.000 & 143 \\
Hypothesis 4 & Cooperation's \& Resources & 0.311 & 0.000 & 143 \\
Hypothesis 5 & Processes & 0.278 & 0.000 & 143 \\
\hline
\end{tabular}

As we can observe from Table 5, the 1-tailed test confirms all five hypotheses, which means there are some strong correlations between enabling employees and leadership, academic qualification, policy and strategy, cooperation and process. Table 6 shows the results of regression model and the results also reject the null hypothesis when the significance level is one percent. Table 7 shows the slops of our regression model. As we can observe, all t-students are valid and null hypothesis are all rejected.

Table 6

Variant Analysis of Hypothesizes of Regression model of criterions of organizational excellence model and employees of East Azerbaijan Mehr Bank enabling

\begin{tabular}{ccclllll}
\hline$\propto=0.01$ & $\mathrm{R}$ & $\mathrm{R}^{2}$ & Adjusted $^{2}$ & Standard Error & $\mathrm{F}$ & Meaningfully level & Test result \\
\hline Hypothesis 1 & 0.298 & 0.089 & 0.082 & 8.323 & 13.724 & 0.000 & $\mathrm{H}_{0}=$ False \\
Hypothesis 2 & 0.353 & 0.125 & 0.119 & 8.156 & 20.131 & 0.000 & $\mathrm{H}_{0}=$ False \\
Hypothesis 3 & 0.296 & 0.088 & 0.810 & 8.327 & 13.564 & 0.000 & $\mathrm{H}_{0}=$ False \\
Hypothesis 4 & 0.311 & 0.097 & 0.091 & 8.285 & 15.151 & 0.000 & $\mathrm{H}_{0}=$ False \\
Hypothesis 5 & 0.278 & 0.077 & 0.070 & 8.376 & 11.764 & 0.000 & $\mathrm{H}_{0}=$ False \\
\hline
\end{tabular}

\section{Table 7}

Parameters coefficients of criterions of organizational excellence model and employees of east Azerbaijan Mehr bank enabling

\begin{tabular}{lllll}
\hline Variable & $\beta$ Line Slope & Calculated T & Meaningfully Level & Result \\
\hline Leadership & 0.387 & 3.705 & 0.000 & $H_{0}=$ False \\
Academic qualification & 0.425 & 4.487 & 0.000 & $H_{0}=$ False \\
Policy and Strategy & 0.674 & 3.683 & 0.000 & $H_{0}=$ False \\
Cooperation's and Resources & 0.862 & 3.892 & 0.000 & $H_{0}=$ False \\
Processes & 0.587 & 3.430 & 0.000 & $H_{0}=$ False \\
\hline
\end{tabular}

In summary, the EFQM criteria of organizational excellence model have been proven to be effective for enabling east Azarbijan banks' employees and the following suggestion could be made to improve the efficiency of the private banks,

\section{- Leadership enabler criterion}

1. Managers and leaders of institute create mission, perspective, values and ethical principles based on organizational excellence laws and they play pattern roles. Managers of Mehr Bank could help employees perform their jobs and their enabling through prepare affirmative environment and intimacy and trusting culture reinforcement.

2. They could reinforce excellence culture among employees to help them increase their abilities. 
3. They could be effective on increasing people stimulus and enablement with on time and sufficient appreciation of employees individual and team cooperation.

4. They could provide immediate help by listening and answering their requests.

5. They could do the same by helping and protecting their people and their short and long term goals.

\section{- Eligible employees and colleagues enabler criterion}

1. The bank is committed for equal job opportunity and this could help people with more talents to get hired by this bank. It is recommended that human resource management (HRM) carefully follow this rules as part of their duties.

2. The institute must review and analyze its employees' educational requirements to increase their capabilities.

3. The effectiveness of selected educational programs for employees must be analyzed.

4. Any constructive feedback from employees could help HRM build better future opportunities for the organization.

5. Creation of promotional opportunities aimed to employee's cooperation absorbing and protection of innovative and creational treatments at corporation level must be implemented.

\section{- Policy and strategy enabler criterion}

1. The institute can help employees on corporation with creation of suggestions system and common improvement teams therefore it can enable them better.

2. In order to parallelism of organizational and individual goals, the institute must enable employees by involving them in different missions, policy, strategy and perspective design.

\section{- Cooperation and resources enabler criterion}

1. For employee's high level improvement, the people must have authentication on jobs.

2. For employee's safety and health, the institute can assess harmful effects of organization properties.

3. Employees are considered as the main wealth of the institute and managing this intellectual property plays an important role on enabling employees.

\section{- Processes enabler criterion}

1. Employee must learn charting, data flow designing, problem solving methods and necessary educations in their work fields. 
2. They must have enough resources and time opportunities so they could be able to innovate and create.

3. The employee's innovational and creational powers and their key capabilities must be used for designing new services.

4. The people's best experiences must be documented and transferred to employees as patterns and guidance so they could use them.

\section{Conclusion}

The recent deregulation policy in banking industry has resulted the emergence of many private banks into the market in Iran. Therefore, competition among these banks has been growing rapidly and banks are looking for different techniques for customer retention. In this paper, we have presented an empirical study to measure the impact of empowering employees on the performance of the some recently established private bank. The proposed study distributed some questionnaire, consists of two parts, among the employee of this bank. The results indicated that leadership, academic qualification, appropriate policy and strategy, cooperation and processes play important role on empowering and enabling bank's employee.

\section{Acknowledgment}

This paper was financially supported by Islamic Azad university of Bonab and the authors would like to thank their support. A special thanks goes to anonymous referees specially the second one whose comments enriched the content of this research paper.

\section{References}

Cronbach, L. J. (1951). Coefficient alpha and the internal structure of tests. Psychometrika, 16(3), 297-334.

European Foundation for Quality Management (2003). EFQM Model for Business Excellence. EFQM, Brussels.

Kull, T.J., \& Wacker,J. G. (2010). Quality management effectiveness in Asia: The influence of culture. Journal of Operations Management, 28(3), 223-239.

Inman, R.A., Sale, R.S., Green Jr., K.W., \& Whitten, W. (2011). Agile manufacturing: Relation to JIT, operational performance and firm performance. Journal of Operations Management, 29(4), 343-355.

Likert, R. (1932). A Technique for the Measurement of Attitudes. Archives of Psychology, 140, 1-55.

J reskog, K.G., \& S rbom, D. (1996). LISREL 8: User's Reference Guide. Scientific Software, Chicago.

Prajogo, D.I., \& Sohal, A.S. (2004). The multidimensionality of TQM practices in determining quality and innovation performance - an empirical examination. Technovation, 24, 443-453.

Rahman, S. (2004). The future of TQM is past. Can TQM be resurrected? Total Quality Management, 15 (4), 411-422.

Rahman, S., \& Bullock, P. (2005). Soft TQM, hard TQM, and organizational performance relationships: an empirical investigation. Omega, 33, 73-83.

Reed, R., Lemak, D.J., \& Montgomery, J.C. (1996). Beyond Process: TQM content and firm performance. Academy of Management Review, 21 (1), 173-201.

Sun, H. (1999). Diffusion and contribution of total quality management: an empirical study in Norway. Total Quality Management, 10 (6), 901-914. 
Yong, J., \& Wilkinson, A. (2001). Rethinking total quality management. Total Quality Management, 12(2), 247-258.

Yusof, S. M., \& Aspinwall, E. (2000). Total quality management implementation frameworks: comparison and review. Total Quality Management, 11(3), 281-294.

Westlund, A.H. (2001). Measuring environmental impact on society in the EFQM system. Total Quality Management, 12 (1), 125-135.

Whetten DA, \& Cameron KS. (1994). Developing management skills, $5^{\text {th }}$ ed., Upper Saddle river, NJ: Prentice Hall.

Zhang, Z. (2000). Developing a model of quality management methods and evaluating their effects on business performance. Total Quality Management. 11 (1), 129-137. 